\title{
Revisiting of the Epidemiology of Obesity among Primary School Children in Egypt
}

\author{
WESAM S. MORAD, M.D.* and ALLIF ALLAM, M.D.** \\ The Departments of Epidemiology \& Preventive Medicine* and Pediatric Hepatology**, National Liver Institute, \\ Menoufia University, Menoufia, Egypt
}

\begin{abstract}
Background: Childhood obesity has more than tripled in the past 30 years. The prevalence of obesity among children aged 6 to 11 years increased from $6.5 \%$ in 1980 to $19.6 \%$ in 2016 the prevalence of obesity in all age groups has increased dramatically over the past 30 years, such that overweight and obesity are considered to be a major public health concern in many countries.
\end{abstract}

Aim of Study: This study aims to assess the prevalence of obesity among children of primary schools in Menoufia Governorate.

Patients and Methods: Across sectional field study was carried out on 7629 Egyptian children to assess prevalence of overweight and obesity among primary school children at age of 6-12 years live in Menoufia Governorate in which 5 schools was randomly selected from rural and 5 schools from urban areas including male and female children. Each child in the study was subjected to medical history, general examination and Anthropometric measurements. Study was done from the first of October 2017 to the end of November 2018 in Menoufia Governorate.

Results: This study showed $12.2 \%$ of the subjects were overweight and $8.6 \%$ were obese. From this study it was concluded that females' subjects were more obese $(9.7 \%)$ than male subjects $(7.5 \%)$ Elder children (9-12 years) were more obese than younger children $(6-<9$ years). Urban residence children with higher socioeconomic standard, studied in private schools, ate fast foods and with sedentary life style showed more obesity than other children.

Conclusions: It is evident that there is correlation between gender, residence, higher socioeconomic standard and fast food intake and development of obesity in primary school children.

Recommendations: From this study it was recommended that there is an increased need to spread community awareness regarding obesity, its consequences, emphasizing on measures of obesity prevention among children, youth and their families, through promoting healthy diet and promoting physical activities.

Correspondence to: Dr. Wesam S. Morad, E-Mail: wesammorad@yahoo.com
Key Words: Obesity - Body mass index - Socioeconomic standard-Anthropometric measures - Primary school children.

\section{Introduction}

OBESITY is defined as an excessive accumulation of body fat. Obesity is present when total body weight is more than 25 percent fat in boys and more than 32 percent fat in girls. Although childhood obesity is often defined as a weight-for-height in excess of 120 percent of the ideal, skinfold measure are more accurate determinants of fatness [1].

According to the childhood overweight and obesity prevalence continues to rise. Currently, $33.4 \%$ of children aged 2-19 are at risk of overweight. If the data is further broken down by race and sex, we see that boys, 2-19 years, have the highest male rates of overweight and obesity, while black girls, 2-19 years, have the highest female prevalence of obesity and overweight [2] .

Body Mass Index (BMI) is a ratio between weights in kilo grams divided by square of height in meters. It's the standard measure for assessing obesity in children and adolescents. It is a reliable index with reasonable measurements and clinical validity in children and adolescent [3].

Childhood obesity has more than tripled in the past 30 years. The prevalence of obesity among children aged 6 to 11 years increased from $6.5 \%$ in 1980 to $19.6 \%$ in 2008 [4].

The causes of obesity are multfactorial and include genetic predisposition, sedentary life style, over eating, fast food diet, lack of adequate nutritional education, school environment and advertising and marketing of unhealthy foods [5] 
It is well-accepted that childhood obesity relates to adulthood overweight/obesity. There is evidence that higher BMI percentiles (greater than the 99 th percentile) in children are associated with increased health risks [6].

Not all obese infants become obese children, and not all obese children become obese adults. However, the prevalence of obesity increases with age among both males and females, and there is a greater likelihood that obesity beginning even in early childhood will persist through the life span [7].

As with adult-onset obesity, childhood obesity has multiple causes centering on an imbalance between energy in (calories obtained from food) and energy out (calories expended in the basal metabolic rate and physical activity). Childhood obesity most likely results from an interaction of nutritional, psychological, familial, and physiological factors [8].

It is commonly agreed that prevention is easier and better than cure. So, obesity prevention is the primary and most obvious strategy to control this disease. As the healthy diet and regular exercise are the corner stone of over all good health for prevention of childhood obesity [9].

Must encourage children to engage in health promoting behaviors while also protecting their positive feelings about their bodies promoting dietary changes in school or community policies may be less likely to make individual children feel stigmatized or punished [10].

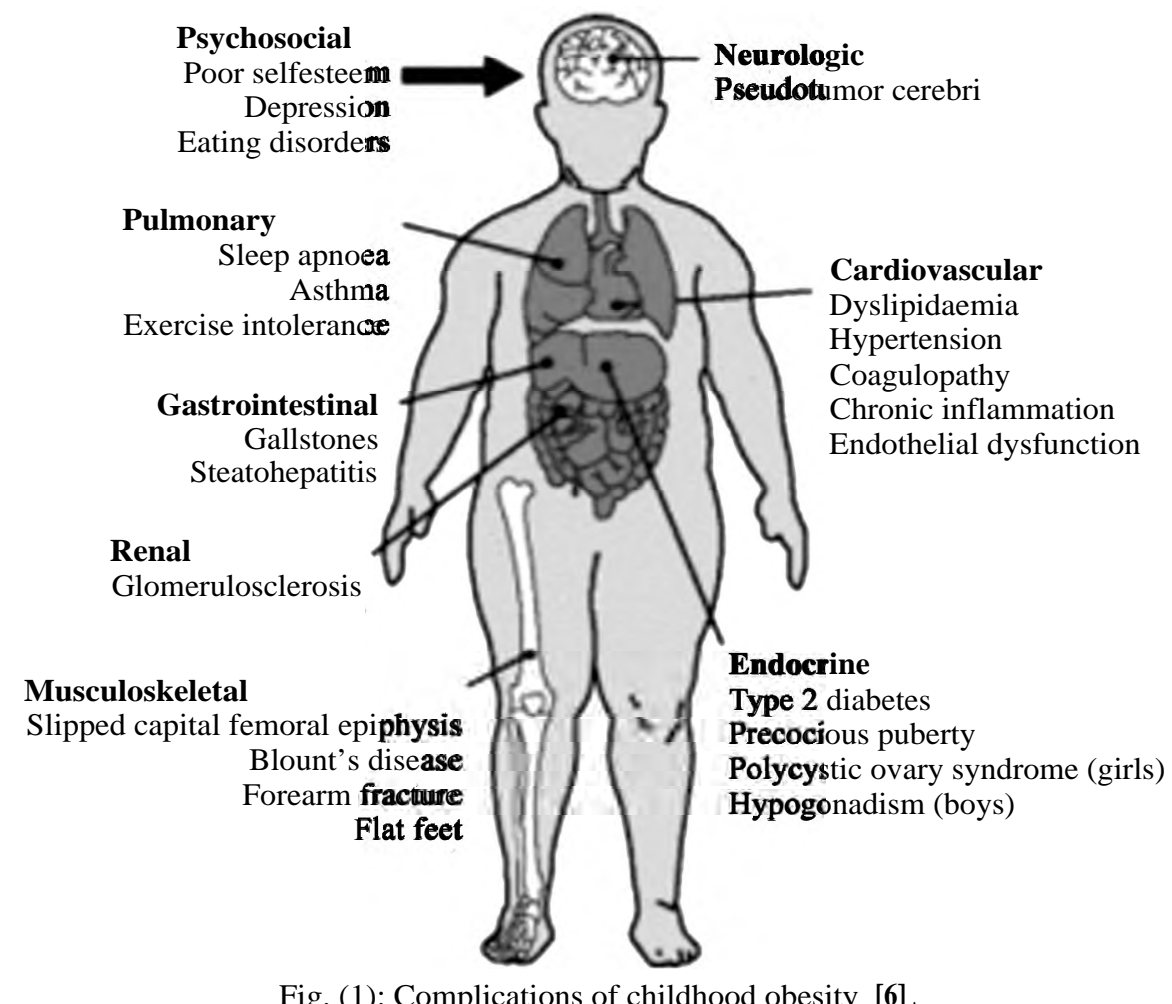

\section{Patients and Methods}

This was a field study which was conducted on 7629 apparently healthy children aged from 612 years, who all were borne and living in Menoufiya Governorate, attending the primary schools in Shebin El-Kom City and Quesina Village, Menoufiya Governorate from duration between the 1 st October 2017 to the end of November 2018. Five randomly selected primary schools from Shebin El-Kom City and other five randomly selected primary schools from Quesina Village including both male and female children to show population in the Menoufiya Governorate and considered legible for entry into the study, if they met the following criteria; age between 6-12 years, born and live in Menoufiya Governorate and apparently healthy children. Children below the age 6 years or with any apparent disorders were excluded from the study. Legal permission was taken from each school management system and the Ministry of Education to assess the prevalence of obesity among these school children'. Each student was subjected to full history taking, clinical examination, growth assessment; weight, height and Body Mass Index (BMI) were assessed and were plotted 
on Egyptian growth charts and lastly laboratory investigations were also done included Lipid profile; serum cholesterol, triglycerides, LDL and hemoglobin level.

Child history was taken which included personal history; a standardized questionnaire with questions to collect information about age, sex, education and occupation of the parents and family income to assess socioeconomic standard of family [11]

Dietary history of the child which was included eating habits and preference of special types of food as fresh vegetables, citrus fruits, canned food, shell fish, meat, take breakfast or not. Physical activity and duration of playing play station, computer or mobile games and watching television were also addressed. Also special habits of the child like any habits of medical importance such as smoking or drug abuse.

Child clinical examination, in which each child was submitted in complete clinical examination, included general examination, heart, chest and abdominal and neurological examination to exclude any endocrinal or any genetic disorders which would affect the body weight or cardiovascular system.

Child anthropometric measurement which was included:

Child body weight which is a growth parameter and a good index of acute and chronic nutritional status. Weight is evaluated for age and child height which was measured without the shoes and the child took a breath, relaxed, the shoulders were stretched up to be as tall as possible, then we put each child weight and height measurement of the children on Egyptian growth charts, 2012 which interpreted as followed; child below ${ }^{3 r d}$ Egyptian centile was considered below normal (abnormal), child between ${ }^{3 \mathrm{rd}}$ and 97 th centile was considered normal and child above 97 th Egyptian centile: Above normal (abnormal)

Laboratory examination of child blood in which all children were subjected to lipid profile; serum cholesterol, triglycerides, LDL and hemoglobin level estimation; which was assessed for every child using hemoglobin spectrophotometer (HemoCue, Sweden). Blood sample was performed on capillary blood from the fingertip of each child after discharge of the first drop by painless sterile safety blood lancets.

An obese child: Is defined as one with BMI more than $2 \mathrm{SD}$ of the reference median, an overweight child is defined as one with BMI more than $1 \mathrm{SD}$ of the reference median, child with thinness is defined as one with BMI less than 2SD of the reference line and child with severe thinness is defined as one with BMI less than -3SD of the reference line [12].

Statistical analysis of the data were collected and analyzed using Epi-info Version 6 and SPSS (Statistical Package for Social Science) Version 25 in which Chi square test was used for qualitative data while student $t$-test and Mann Whitney test was used for quantitative normally distributed and not normally distributed data respectively and for all the statistical tests $p$-value of $<0.05$, was considered significant. Data were expressed in terms of standard deviation scores (z-scores) using WHO AnthroPlus software provided by WHO website, the Z-score cut-off points recommended by WHO were used [12]

\section{Results}

Total screened children were 7629,3751 $(49.2 \%)$ were males, $3878(50.8 \%)$ were females, $3809(49.9 \%)$ from 6-9 years and $3820(50.1 \%)$ from $10-12$ years. $2515(32.97 \%)$ from rural and $5114(67.03 \%)$ from urban area. 1217 (15.95\%) were of high socioeconomic standard and 2262 (29.65\%) of low socioeconomic standard. 6419 (84.1\%) from governmental schools and 1210 (15.9\%) from private schools. 5517 (72.3\%) children of normal weight, 868 (11.4\%) overweight and $657(8.6 \%)$ obese. There were highly statistical significant association between weight and body mass index with gender, residence, socioeconomic standard and school type ( $p$-value $<0.01$ ) while there were only highly statistical association between child height and gender ( $p$-value $<0.01)$ and no statistical association between height and either residence, or socioeconomic standard or type of school ( $p$-value >0.05). In this study it was found that in association between BMI z-score and either gender, residence, type of school or socioeconomic standard, female children, from urban area, of high socioeconomic standard and from private schools had highly statistical significant extra positive deviations from mean than other children ( $p$-value $<0.01$ ). In all age classes' obesity was more prevalent in female children than male children. Also obesity was more prevalent in the age of 7-9 years in both sexes. In this study there were no correlation between BMI and BMI z-score and studied laboratory data (cholesterol, TGs, HDL, LDL and HB) among 657 obese children ( $p$-value >0.05). There were no statistical significant difference between BMI-scores <2SD (528 child) and >3SD (129 child) and neither cholesterol nor TGs nor HDL nor LDL ( $p$-value >0.05). 
Table (1): General descriptive data of studied sample.

\begin{tabular}{lll}
\hline & $\mathrm{N}$ & $\%$ \\
\hline Age class (years): & & \\
$6-<7$ & 1338 & 17.54 \\
$7-<8$ & 1266 & 16.59 \\
$8-<9$ & 1205 & 15.79 \\
$9-<10$ & 1302 & 17.07 \\
$10-<11$ & 1299 & 17.03 \\
$11-12$ & 1219 & 15.98 \\
Gender: & & \\
Male & 3751 & 49.17 \\
Female & 3878 & 50.83 \\
Residence: & & \\
Rural & 2515 & 32.97 \\
Urban & 5114 & 67.03 \\
Socioeconomic standard: & & \\
$\quad$ Very low & 254 & 3.33 \\
Low & & \\
Intermediate & 2262 & 29.65 \\
High & 3893 & 51.03 \\
Very high & 1217 & 15.95 \\
School: & 3 & 0.04 \\
Governmental & & \\
Private & 6419 & \\
\hline Total sample size & 1210 & \\
\hline & & 7629 \\
\hline
\end{tabular}

Weight-for-age reference z-scores were not available beyond age 10 (120 months) because this indicator does not distinguish between height and body mass in an age period where many children are experiencing the pubertal growth spurt and might appear as having excess weight (by weightfor-age) when in fact they were just tall. (WHO, 2007).
Table (2): Classification of anthropometric measurements of studied children according to $\mathrm{z}$-scores.

\begin{tabular}{lll}
\multicolumn{2}{c}{$\mathrm{N}$} & $\%$ \\
\hline \multicolumn{2}{c}{ Height-for-age z-score $(\mathrm{X} \pm \mathrm{SD})=(-1.12 \pm 0.6)$} \\
\hline $\begin{array}{l}\text { Height/age } \text { z-score class: } \\
\text { <3SD }\end{array}$ & 16 & \\
<2SD & 458 & 0.21 \\
Normal & 7134 & 6.0 \\
>1 SD & 12 & 93.51 \\
>2SD & 8 & 0.16 \\
>3 SD & 1 & $0.1 \%$ \\
\hline
\end{tabular}

Weight-for-age $\mathrm{z}$-score $(\mathrm{X} \pm \mathrm{SD})=(-0.06 \pm 0.9)$

\begin{tabular}{lll}
\hline $\begin{array}{l}\text { Weight/age } \\
\text { <3SD }\end{array}$ & & \\
<2SD & 40 & 0.52 \\
Normal & 511 & 6.69 \\
>1 SD & 4017 & 52.65 \\
>2SD & 612 & 8.02 \\
>3 SD & 111 & 1.45 \\
& 1681 & 22.02 \\
\hline
\end{tabular}

BMI-for-age z-score $(\mathrm{X} \pm \mathrm{SD})=(0.7 \pm 1.1)$

\begin{tabular}{|c|c|c|}
\hline \multicolumn{3}{|l|}{ BMI z-score class: } \\
\hline$<3 \mathrm{SD}$ (severe thinness) & 41 & 0.54 \\
\hline$<2 \mathrm{SD}$ (thinness) & 546 & 7.16 \\
\hline Normal & 5517 & 72.32 \\
\hline >1SD (overweight) & & 11.38 \\
\hline$>2 \mathrm{SD}$ (obesity) & \begin{tabular}{l|l}
528 & 657
\end{tabular} & \begin{tabular}{l|l}
$6.9 \%$ & 8.6
\end{tabular} \\
\hline$>3 \mathrm{SD}$ (obesity) & 129 & $1.69 \%$ \\
\hline \multicolumn{3}{|l|}{ Totes: } \\
\hline \multicolumn{3}{|c|}{$\begin{array}{l}\text { - Results were obtained using WHO reference z-score tables and } \\
\text { charts for anthropometric measurements for children }(5-19) \text { years } \\
\text { old. (WHO, 2007). } \\
\text { - Normal coincides with parameters fall between }(-2 \text { SD and } 1 \text { SD) or } \\
\text { (3rd and 85th percentile) } \\
<3 \text { SD coincides with }<1 \text { st percentile. } \\
<2 \text { SD coincides with }<3 \text { rd percentile. } \\
>1 \text { SD coincides with }>85 \text { th percentile. } \\
>2 \text { SD coincides with }>97 \text { th percentile. } \\
>3 \text { SD coincides with }>99 \text { th percentile. }\end{array}$} \\
\hline
\end{tabular}

Table (3): Comparison between anthropometric measurements of children regarding sex, residence, school type and socioeconomic standard.

\begin{tabular}{|c|c|c|c|c|c|c|c|c|c|}
\hline & \multicolumn{3}{|c|}{ Weight (Kg) } & \multicolumn{3}{|c|}{ Height $(\mathrm{Cm})$} & \multicolumn{3}{|c|}{ BMI } \\
\hline & Mean & SD & $p$-value & Mean & SD & $p$-value & Mean & SD & $p$-value \\
\hline \multicolumn{10}{|l|}{ Gender: } \\
\hline Male & 29.4 & 7.3 & \multirow[t]{2}{*}{$<0.01 * *$} & 127.3 & 9.3 & \multirow[t]{2}{*}{$<0.01 * *$} & 18.5 & 2.9 & \multirow[t]{2}{*}{$<0.01 * *$} \\
\hline Female & 30.8 & 8.9 & & 127.9 & 9.2 & & 18.9 & 3.5 & \\
\hline \multicolumn{10}{|l|}{ Residence: } \\
\hline Rural & 28.3 & 6.9 & \multirow[t]{2}{*}{$<0.01 * *$} & 125.9 & 8.4 & \multirow[t]{2}{*}{$>0.05$} & 17.9 & 2.9 & \multirow[t]{2}{*}{$<0.01 * *$} \\
\hline Urban & 29.8 & 8.2 & & 125.9 & 9.7 & & 18.8 & 3.4 & \\
\hline \multicolumn{10}{|l|}{ School: } \\
\hline Governmental & 30.2 & 7.9 & \multirow[t]{2}{*}{$<0.01 * *$} & 127.4 & 9.4 & \multirow[t]{2}{*}{$>0.05$} & 18.3 & 3.5 & \multirow[t]{2}{*}{$<0.05^{*}$} \\
\hline Private & 30.1 & 8.7 & & 126.7 & 9.8 & & 18.5 & 3.4 & \\
\hline \multicolumn{10}{|c|}{ Socioeconomic standard: } \\
\hline Intermediate & 30.0 & 7.9 & \multirow[t]{5}{*}{$<0.01 * *$} & 125.8 & 9.7 & \multirow[t]{5}{*}{$>0.05$} & 18.4 & 3.2 & \multirow[t]{5}{*}{$<0.01 * *$} \\
\hline High & 30.9 & 7.8 & & 125.9 & 9.1 & & 18.9 & 3.4 & \\
\hline Very high & 30.3 & 18.1 & & 126.9 & 16.4 & & 18.3 & 6.3 & \\
\hline Low & 29.6 & 8.5 & & 128.4 & 10.2 & & 18.4 & 3.7 & \\
\hline Very low & 29.9 & 9.4 & & 127.2 & 9.5 & & 17.6 & 3.6 & \\
\hline
\end{tabular}


Female children tend to have significant more weight, height and BMI means than male sex. Children from rural area had less weight and BMI means than those in urban areas, weight and BMI means were significantly higher in high socioeconomic level and in children of private schools.

Table (4): Comparison between different demographic and risk factors of obesity regarding BMI z-score classes.

\begin{tabular}{|c|c|c|c|c|c|c|c|c|c|c|c|c|c|}
\hline & \multicolumn{12}{|c|}{ BMI z-score class } & \multirow{3}{*}{$\begin{array}{c}p- \\
\text { value }\end{array}$} \\
\hline & \multicolumn{2}{|c|}{$<3 \mathrm{SD}$} & \multicolumn{2}{|c|}{$<2 \mathrm{SD}$} & \multicolumn{2}{|c|}{ Normal } & \multicolumn{2}{|c|}{$>1 \mathrm{SD}$} & \multicolumn{2}{|c|}{$>2 \mathrm{SD}$} & \multicolumn{2}{|c|}{$>3 \mathrm{SD}$} & \\
\hline & $\mathrm{N}$ & $\%$ & $\mathrm{~N}$ & $\%$ & $\mathrm{~N}$ & $\%$ & $\mathrm{~N}$ & $\%$ & $\mathrm{~N}$ & $\%$ & $\mathrm{~N}$ & $\%$ & \\
\hline \multicolumn{14}{|l|}{ Gender: } \\
\hline Male (3750) & 39 & 1.0 & 306 & 8.2 & 2710 & 72.3 & 415 & 11.1 & 182 & 4.9 & 98 & 2.6 & $<0.01 * *$ \\
\hline Female (3879) & 126 & 3.2 & 240 & 7.9 & 2683 & 69.2 & 453 & 11.7 & 346 & 8.9 & 31 & 0.8 & \\
\hline \multicolumn{14}{|l|}{ Residence: } \\
\hline Rural (2516) & 36 & 1.4 & 532 & 21.1 & 1671 & 66.4 & 156 & 6.2 & 99 & 3.9 & 22 & 0.9 & $<0.01 * *$ \\
\hline Urban (5113) & 5 & 0.1 & 14 & 0.3 & 3845 & 75.1 & 712 & 13.9 & 429 & 8.4 & 108 & 2.1 & \\
\hline \multicolumn{14}{|l|}{ Type of school: } \\
\hline Governmental (6418) & 40 & 0.6 & 546 & 8.5 & 4691 & 73.1 & 701 & 10.9 & 356 & 5.5 & 84 & 1.3 & $<0.01 * *$ \\
\hline Private (1211) & 1 & 0.08 & 0 & 0.0 & 826 & 68.2 & 167 & 13.8 & 172 & 14.2 & 45 & 3.7 & \\
\hline \multicolumn{14}{|l|}{ Socio-economic standard: } \\
\hline Intermediate (2700) & 27 & 0.3 & 361 & 13.4 & 2215 & 82.0 & 10 & 0.4 & 42 & 1.6 & 45 & 1.7 & $<0.01 * *$ \\
\hline High (1593) & 7 & 0.4 & 3 & 0.2 & 961 & 60.3 & 372 & 23.4 & 221 & 13.9 & 29 & 1.8 & \\
\hline Very high (1314) & 6 & 0.5 & 167 & 12.7 & 1098 & 83.6 & 0 & 0.0 & 19 & 1.8 & 24 & 1.8 & \\
\hline Low (1887) & 1 & 0.05 & 7 & 0.4 & 1149 & 60.9 & 465 & 24.6 & 235 & 12.5 & 30 & 1.6 & \\
\hline Very low (135) & 0 & 0.0 & 7 & 5.2 & 95 & 70.4 & 21 & 15.6 & 10 & 7.4 & 2 & 1.5 & \\
\hline \multicolumn{14}{|l|}{ Fast food intake: } \\
\hline Positive (2061) & 3 & 0.15 & 2 & 0.09 & 800 & 38.8 & 693 & 33.6 & 356 & 17.3 & 207 & 10.0 & $<0.01 * *$ \\
\hline Negative (5568) & 36 & 0.65 & 544 & 9.8 & 4691 & 84.2 & 101 & 1.8 & 172 & 3.09 & 24 & 0.43 & \\
\hline \multicolumn{14}{|l|}{ Lack of physical activity: } \\
\hline Positive (5205) & 2 & 0.04 & 44 & 0.85 & 3800 & 73.0 & 762 & 14.6 & 479 & 9.2 & 118 & 2.3 & $<0.01 * *$ \\
\hline Negative (2424) & 39 & 1.6 & 502 & 20.7 & 1716 & 70.8 & 106 & 4.4 & 49 & 2.02 & 12 & 0.49 & \\
\hline
\end{tabular}

**: Highly significant. - Chi square test was the statistical test used.

Regarding BMI z-score, female children, from urban area and children from higher socioeconomic levels, from private schools, with fast food intake and with lacking physical activity had significant more positive deviations from mean than other children ( $p$-value $<0.01)$.

Table (5): Prevalence studies of obesity. Age and sex specific prevalence of obesity in children aged 6-12 years with 95\% confidence interval: (Obesity defined according to WHO as BMI z-score >2SD).

\begin{tabular}{|c|c|c|c|c|c|c|c|c|c|c|}
\hline \multirow[b]{2}{*}{ Age } & \multicolumn{3}{|c|}{ Both sex } & \multicolumn{3}{|c|}{ Male (3750) } & \multicolumn{3}{|c|}{ Female (3879) } & \multirow{2}{*}{$\begin{array}{l}\text { Male/female } \\
\text { ratio }\end{array}$} \\
\hline & $\mathrm{N}$ & Prevalence & $95 \% \mathrm{CI}$ & $\mathrm{N}$ & Prevalence & $95 \% \mathrm{CI}$ & $\mathrm{N}$ & Prevalence & $95 \% \mathrm{CI}$ & \\
\hline All groups & 657 & $8.6 \%$ & $7.5-19.9 \%$ & 281 & $7.5 \%$ & $6.2-17.6 \%$ & 376 & $9.7 \%$ & $9.0-29.3 \%$ & 0.75 \\
\hline 6 years & 114 & $9.5 \%$ & $7.0-24.1 \%$ & 64 & $7.9 \%$ & $6.2-17.6 \%$ & 50 & $8.5 \%$ & $9.0-29.3 \%$ & 1.28 \\
\hline 7 years & 124 & $10 \%$ & $9.6-23.3 \%$ & 56 & $8.5 \%$ & $5.5-17.5 \%$ & 68 & $9.8 \%$ & $7.1-25.8 \%$ & 0.82 \\
\hline 8 years & 103 & $9 \%$ & $8.1-14.3 \%$ & 34 & $5.6 \%$ & $4.7-16.4 \%$ & 69 & $9.9 \%$ & $6.6-20.1 \%$ & 0.49 \\
\hline 9 years & 115 & $9.6 \%$ & $4.2-13.7 \%$ & 55 & $8.4 \%$ & $3.5-13.8 \%$ & 60 & $9.2 \%$ & $8.7-24.6 \%$ & 0.92 \\
\hline 10 years & 112 & $9.6 \%$ & $7.5-15.1 \%$ & 52 & $8.2 \%$ & $6.2-13.7 \%$ & 60 & $9.2 \%$ & $8.1-27.7 \%$ & 0.87 \\
\hline 11 years & 89 & $7.2 \%$ & $6.1-20.2 \%$ & 20 & $3.8 \%$ & $2.9-12.6 \%$ & 69 & $9.9 \%$ & $8.5-24.1 \%$ & 0.29 \\
\hline
\end{tabular}

- In all age classes' obesity was more prevalent in female children than male children. Also obesity was more prevalent in the age of 7-9 years in both sexes. 
Table (6): Clinical data of obese children sample (657 children) (presented in numerical manner).

\begin{tabular}{llc}
\hline & Mean & Standard deviation \\
\hline WT & 50.8 & 32.1 \\
HT & 135.7 & 11.4 \\
BMI & 45.6 & 201.1 \\
Height z-score & 1.12 & 1.4 \\
Weight z-score & 3.3 & 1.2 \\
BMI z-score & 2.69 & 0.57 \\
CHOLES & 175.2 & 35.2 \\
TG & 102.3 & 55.1 \\
HDL & 82.5 & 22.7 \\
LDL & 69.3 & 24.2 \\
HB & 12.1 & 0.72 \\
\hline
\end{tabular}

Table (7): Pearson correlation between studied laboratory data and BMI \& BMI z-score among obese children (657 children)

\begin{tabular}{lcccc}
\hline & \multicolumn{2}{c}{ BMI } & \multicolumn{2}{c}{ BMI z-score } \\
\cline { 2 - 5 } & \multicolumn{1}{c}{$r$} & $p$-value & $r$ & $p$-value \\
\hline BMI & & & & \\
BMI z-score & -0.099 & $>0.05$ & & \\
Cholesterol & -0.071 & $>0.05$ & -0.119 & $>0.05$ \\
TGs & -0.114 & $>0.05$ & -0.146 & $>0.05$ \\
HDL & 0.042 & $>0.05$ & -0.192 & $>0.05$ \\
LDL & -0.066 & $>0.05$ & 0.018 & $>0.05$ \\
HB & -0.131 & $>0.05$ & 0.002 & $>0.05$ \\
\hline
\end{tabular}

No significant correlations found ( $p$-value $>0.05$ ).

Table (8): Comparison between normal and abnormal blood lipid levels regarding BMI z-score categories among obese children (657 children).

\begin{tabular}{lccccc}
\hline & \multicolumn{4}{c}{ BMI z-score class } & \\
\cline { 2 - 4 } & \multicolumn{3}{c}{$p$ - } \\
\cline { 2 - 5 } & No. & $\%$ & No. & $\%$ & \\
\cline { 2 - 5 } & value \\
\hline Cholesterol class: & & & & & \\
$\quad$ Normal & 348 & 65.9 & 95 & 73.6 & $>0.05$ \\
$\quad$ Abnormal & 180 & 34.1 & 34 & 26.4 & \\
Triclyceride class: & & & & & \\
$\quad$ Normal & 385 & 72.9 & 112 & 86.8 & $>0.05$ \\
$\quad$ Abnormal & 143 & 27.1 & 17 & 13.2 & \\
HDL class: & & & & & \\
$\quad$ Normal & 348 & 65.9 & 77 & 59.7 & $>0.05$ \\
$\quad$ Abnormal & 180 & 34.1 & 52 & 40.3 & \\
LD class: & & & & & \\
$\quad$ Normal & 503 & 95.3 & 129 & 100.0 & $>0.05$ \\
$\quad$ Abnormal & 25 & 4.7 & 0 & 0.0 & \\
\hline
\end{tabular}

- Chi square test was the statistical test used.

- No statistical significant difference was found ( $p$-value $>0.05$ ).

\section{Discussion}

Childhood obesity has more than tripled in the past 30 years. The prevalence of obesity among children aged 6 to 11 years increased from $6.5 \%$ in 1980 to $19.6 \%$. Also fast food has become a prominent feature of children diet and it is increasing throughout the world and obesity is considered now as one of the most important predisposing factors for many chronic diseases [4].

Once children (and adults) are obese, it is often difficult for them to lose weight through physical activity and healthy diet. Preventing weight gain from an early age, i.e. in childhood, is therefore recognized as a strategy that will reap health benefits in the long term [13].

Obesity has negative health impacts in childhood, as well as in the long term. In addition to a higher risk of obesity and NCDs later in life, affected children experience adverse outcomes such as breathing difficulties, increased risk of fractures, hypertension, and early markers of cardiovascular disease, insulin resistance and psychological effects [14].

This stimulated us to perform this study aiming to assess the prevalence of obesity among primary school children. This study was conducted on 7629 Primary School Children in Menoufia GovernorateShebin El-Kom District and Quisena Village, their age ranged from 6-12 years, during period from 1 st October 2017 to 30 th November 2018.

In this study, comparing distribution of students regarding to sex $49.2 \%$ were females and $50.8 \%$ were males. This is concordance with results found by El-Shafie et al., [15] in El-Bagour district study that the distribution of females was high than males.

With regards the BMI for age Z-score of children in this study it was found that 41 children $(0.54 \%)<3$ SD (sever thinness), 546 children $(7.16 \%)<2 \mathrm{SD}$ (thinness), while 868 children $(11.38 \%)$ were $>1$ SD (over weight) were 528 children $(6.9 \%),>2 \mathrm{SD}$ (obese) and 129 children (1.69\%) were >3SD (obese). 657 (8.6\%) children were all obese children.

In this study the percentage of overweight and obesity were higher than that reported in previous Egyptian study conducted by El-Masry, [16] which showed the prevalence of children overweight and obesity in Egypt was 10.8\% and 5.3\% respectively. On the other hand Abou Ghazy et al., [17] reported that the percentage of $37.4 \%$ overweight and $20.4 \%$ obese children in Qalubia governorate.

The percent of obesity in the present study was 8.5\% (is higher than values described by El-Masry, [16]. This variation might be partially attributed to 
the difference in standard curves used for comparison in which El-Masry, [16] used American standard curves while the present work used BMI for age $\mathrm{Z}$ score furthermore, the period between previous studies and the present works this period had a role in the rise of obesity percentage.

While the percent of obesity in the current work is lower than Abou Ghazy study, [17] which may be due to the difference in sample size which was 500 students in Abou Ghazy study and 7629 students in this study also the difference in age group between the students of both studies might be the cause of different results.

Regarding BMI-Z-score classes we found prevalence of overweight and obesity among female subject $(11.7 \%$ \& $9.7 \%)$ respectively higher than male subject $(11.1 \% \& 7.5 \%)$ respectively this could be due to reduced activity levels of girls in the school or out the school in which these results were confirmed by Salazar-Martinez et al., [18] who compared over-all prevalence of overweight and obesity in Egypt and Mexico, they found that in Mexican sample $18 \%$ of boys and $21 \%$ of girls were overweight and $11 \%$ of boys and $9 \%$ of girls were obese. In the Egyptian sample, $7 \%$ of boys and $18 \%$ of girls were overweight and $6 \%$ of boys and $8 \%$ of girls were obese. On the contrary to our results Abou Ghazy et al., [17] reported that the prevalence of obesity among Egyptian school children live in Qalubia was $22.5 \%$ and $18.5 \%$ for males and females respectively their age ranged from 7-15 years. These finding revealed that the difference in age group between the students in both studies might be the cause of the opposite results.

For regarding BMI Z-score classes in association with residence we found percentage of overweight \& obesity $13.9 \% \& 10.5 \%$ respectively in urban children higher than rural children $6.2 \%$ \& $4.8 \%$ with significant difference. This could be explained by dietary variation between urban and rural children. This agree with Jackson et al., [19] who relate the body weight body image to child residence, found that $35 \%$ of the girls were $>$ or $=$ 85 th percentile, while $13 \%$ were $>$ or $=95$ th percentile.

Overweight was more prevalent in urban than rural girls and in those with higher socio-economic status than in lower socio-economic status girls.

This was in contrary to the findings of El-Shafie et al., [9] who stated that there was no change in frequency of sign of malnutrition between urban and rural children.
In this study the prevalence of overweight \& obesity in private schools $13.8 \%$ \& $17.9 \%$ respectively compared to overweight $10.9 \%$ and obesity $6.8 \%$ in governmental schools in which these results went with Hafez et al., [20] findings which reported the prevalence of overweight \& obesity of $11 \%$ and $3.8 \%$ respectively, among children of governmental schools in Cairo.

Socioeconomic status may dictate lifestyle behaviors that result in an increase of childhood obesity. Numerous studies have demonstrated an inverse relationship between obesity and family income, education, or both among adults while our study reported that BMI for age $\mathrm{Z}$ score were increasing with the increase in socio-economic class $(1.8 \%$ of $>2 \mathrm{SD})$ were from the very high standard, (13.9\% of $>2 \mathrm{SD})$ were from the high class, $(1.6 \%$ of $>2 \mathrm{SD})$ from intermediate class, $(12.5 \%$ of $>2 \mathrm{SD})$ were from the low class, $(7.4 \%$ of $>2 \mathrm{SD}$ ) were from the very low class. This was confirmed by Batch and Baur, [21] who reported that in some developed countries, poorer children or those who live in rural settings are more at risk of obesity, whereas in countries undergoing economic transition childhood obesity is associated with a more affluent lifestyle and with living in urban regions.

These results were in contrast these reported by Abdel-Salam, [22] in Egypt, who found that obese children were of low socioeconomic standard.

Also in BMI Z-score classes in association with fast food intake we found in children ate fast foods than other overweight and obese children $1.8 \%$ \& $3.52 \%$ respectively who eat healthy foods with significant difference and those with lacked physical activity the percentage of overweight \& obesity $14.6 \% \& 11.5 \%$ respectively versus percentage of overweight and obese $4.4 \%$ and $2.51 \%$ in those with physical activity respectively, in which these results confirmed the results of Abou Ghazy, [17] who reported that obesity in Qalubia was higher in high socio-economic class this might be explained by unhealthy life style through excessive processed food, artificial juices and soda drinks intake together with less physical activity; prolonged sitting at home playing play station and computer games or watching television advertisements of fast foods among children high socioeconomic standard.

As when the age of the children increases, the interest of their bodies forms increases; we reported that the younger children $(6<9$ years) were more obese than elder children (9-12 years) these findings 
were confirmed by Chrzanowska et al., [23] who estimated that much increase in BMI was found in boys with (7-9) age group and in girls aged 710 years.

\section{Conclusion:}

Obesity prevention focuses in large measure on parents' education. In infancy, parents' education should center on promotion of breast feeding, recognition of signals of satiety, and delayed introduction of solid foods. In early childhood, education should include proper nutrition, selection of lowfat snacks, good exercise/activity habits, and monitoring of watching television. In cases where preventive measures cannot totally overcome the influence of hereditary factors, parent education should focus on building self-esteem and address psychological issues.

\section{Recommendations:}

We finally recommended that there must be an urgent spread of awareness regarding obesity, its consequences, means and methods of prevention and control especially among young children, youth and their families, through promoting healthy life style; healthy diet and physical activities.

\section{References}

1- LOOS R.J. and BOUCHARD C.: FTO the first gene contributing to common forms of human obesity Obes. Rev., 9 (3): 246-50, 2008.

2- NHANES III National health and nutrition examination survey: Department of Health and Human Services, national center for health statistics. National Technical Information service: Springfield VA. USA, 2003-2004.

3- KREBS N.F., HIMES J.H., JACOBSON D. and NICKLAS TAS GUILDAY P.: Assessment of child and adolescent overweight and obesity. Pediatrics, 120: S193-S228, 2007.

4- OGDEN C.L., CARROLL M.D., CURTIN L.R., LAMB M.M. and FLEGAL K.M.: Prevalence of high body mass index in US children and adolescents, (2007-2008). J.A.M.A. 2010* VL. 03 (3): 242-9, 2010.

5- HASSINK S.G.: Childhood obesity: And over view. In Pediatric obesity: Prevention, intervention, and treatment strategies for primary care, ELK Groove Village (IL): American Academy of pediatrics; P. 1-6, 22-5, 2007.

6- FREEDMAN D.S., MEI A., SRINIVASAN S.R., BERENSON G.S. and DIETZ W.H.: Cardiovascular risk factors and excess adiposity among overweight children and adolescents: The Bogalusa Heart Study. The Journal of Pediatrics, 150: 12-17, 2007.

7- WIEGAND S., DANNEMANN A., KRUDE T.L. and GRTITERS A.: Impaired glucose tolerance said type 2, diabetes mellitus: A new field for pediatrics in Europe Int. J. Obes., 29: S136, 2005.

8- BLAINE B.: Does depression cause obesity? A metaanalysis of longitudinal studies of depression and weight control. J. Health Psychol., 13 (8): 1190-7, 2008.
9- EL-SHAFIE M.A., BAHBAH M.H. and RANDA: Recent advances in pathophysiology and management of childhood obesity, master Essay, Facult of Medicine Menoufiya University, 2011.

10- SCHWARTZ M.B., NOVAK S.K. and FIORE S.S.: The impact of removing snacks of low nutritional value from middle schools. Health Educ. Behav., 2009.

11-FAHMY I.S. and El-SHERBINI A.F.: Determining simple parameters for social classifications for health research High institute of public health Alexandria University the bulletin of the high institute of public health Vol. X111No. 5-1983, 1993.

12- WHO: WHO AnthroPlus software provided by WHO website, http://www.who.int/growthref/en/, 2007.

13-American Medical Association: Expert committee recommendations on the assessment, prevention, and treatment of child and adolescent overweight and obesity. Retrieved April 25, 2009 from http://www.ama-assn.org/ama1/pub/ upload/mm/433/ped_obesity_recs.pdf, 2007.

14- DANIELS S.R., ARNETT D.K., ECKEL R.H., et al.: Overweight in children and adolescents: Pathophysiology, consequences, prevention, and treatment Circulatio n.; 111; 1 \$99-2002, 2005.

15- EL-SHAFIE M.A., EL-NEMER M.F., EL-LAHONI D. ALAAM A. and TAMER: Assessment of parasitic infestation and its effect on school performance in El-Bagor center in Menoufiya governorate, Master thesis, Faculty of Medicine, Menoufiya University, 2009.

16- El-Masry S.A.: Nutritional assessment of Egyptian children. Egypt Med. J. N.R.C., 6 (2): 40-9, 2007.

17- ABOU CHAZY H.S., EZZAT A.M., EL-GENDY M.F., SOLIMAN D.R. and ASHRAF: Body mass index as an assessment tool for overweight and obesity in School children in El-Qalubia Governorate, Journal of American Science, 7 (8), 2011.

18- SALAZAR-MARTINEZ E., ALIEN B., FERNANDEZ ORTEGA C., TORRES MEJIA G., GALAL O. and LAZCANO-PONCE E.: Overweight and obesity status among adolescents from Mexico and Egypt. Arch. Med. Res., 37: 535-2, 2006.

19- JACKSON R.T., RASHED M. and SAAD-EIDIN R.: Department of Nutrition and food science, University of Mary land, 3303 Marie Mount Hall, College Park, MD 20742-USA. Int. J. Food Sci. Nutr., 54 (1): 1-11 (ISSN: 0963-7486), 2003.

20- HAFEZ A.S., EI-AWADY M.Y. and HASSAN N.E.: Obesity profile among primary school children in Cairo. The Egyptian Journal of community Medicine, 18: 99119,2000

21- BATCH J.A. and BAUR L.A.: Management and prevention of obesity and its complications in children and adolescents. M.J.A., 182 (3): 130-5, 2005.

22- ABDEL-SALAM S.M.: Family environment and childhood obesity. Master thesis in pediatrics Faculty of Medicine. Ain Shams University, 2002.

23- CHRZANOWSKA M., KOZILE S. and ULIJASZEK S. Changes in BMI and the prevalence of overweight and obesity in children and adolescents in Cracow. Poland, 1971-2000 Economics and Human Biology, 5: 370-8, 2007. 


\section{إعادة النظرفى وبائيات السمنة بين آطفال المدارس الإبتدائية

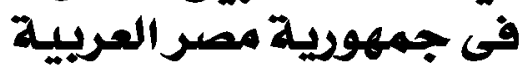

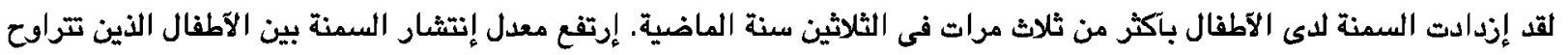

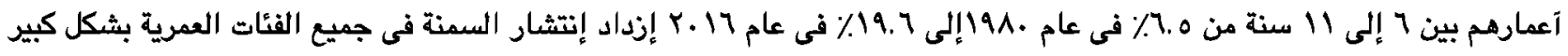

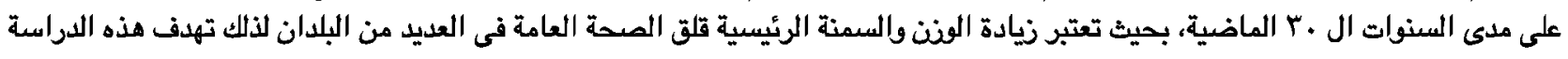

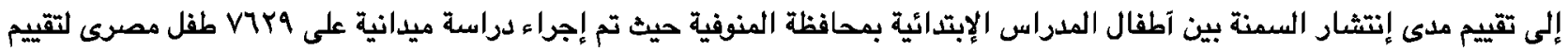

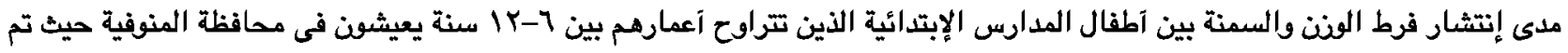

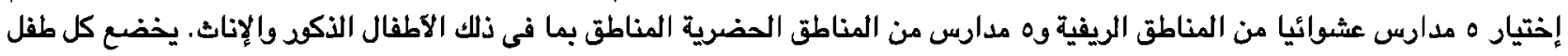

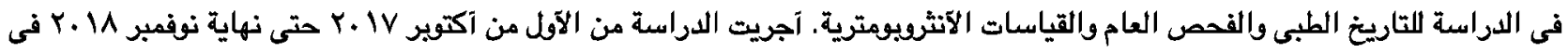

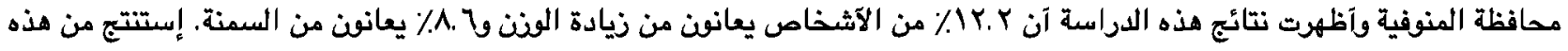

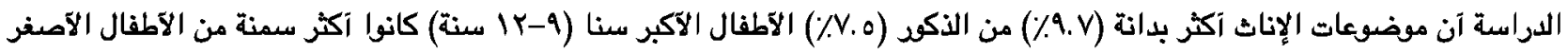

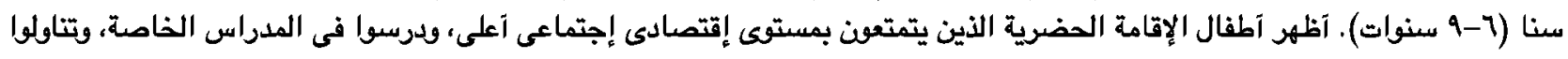

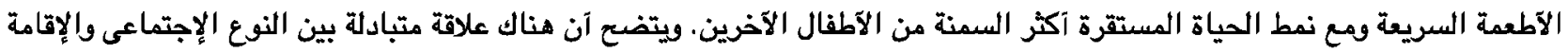

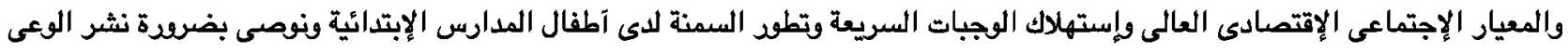

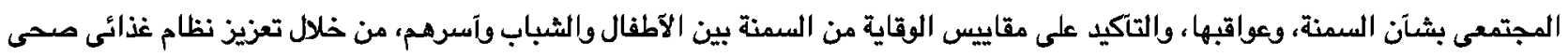

